\title{
Correct interpretation of chemical diagrams requires transforming from one level of representation to another
}

\author{
Gail D Chittleborough \\ David F Treagust \\ ${ }^{a}$ Deakin University, Burwood, Victoria \\ ${ }^{\mathrm{b}}$ Curtin University of Technology, Perth,WA.
}

Contact:

gailc@deakin.edu.au 


\title{
Correct interpretation of chemical diagrams requires transforming from one level of representation to another
}

\begin{abstract}
Volunteer non-major chemistry students taking an introductory university chemistry course $(n=17)$ were interviewed about their understanding of a variety of chemical diagrams. All the students' interviewed appreciated that diagrams of laboratory equipment were useful to show how to set up laboratory equipment. However students' ability to explain specific diagrams at either the macroscopic or sub-microscopic level varied greatly. The results highlighted the poor level of understanding that some students had even after completing both exercises and experiments using the diagrams. The connection between the diagrams of the macroscopic level (equipment, chemicals), the sub-microscopic level (molecular) and the symbolic level (equations) was not always 'considered explicitly by' students. The results indicate a need for chemical diagrams to be used carefully and more explicitly to ensure learner understanding. Correspondingly, students need to interpret visual chemical diagrams using meta-visualisation skills linking the various levels of representation, and appreciating the role of the diagrams in explanations need to be developed.
\end{abstract}




\section{The descriptive and explanatory nature of chemical diagrams does not guarantee understanding}

\section{Introduction}

Chemical diagrams were intentionally introduced into the pre-laboratory exercises in an introductory university course to improve the pedagogical approach to teaching chemistry based on the assumption that students would be better prepared for the laboratory activities through using and interpreting chemical drawings of the chemical equipment. Specifically, the study was designed to investigate how students with limited previous chemistry knowledge interpreted diagrams of chemical equipment at the macroscopic and sub-microscopic levels.

The objective of introducing online pre-laboratory exercises was to have students identify the aim of the weekly experiments, to show students pictures and diagrams of unfamiliar equipment, to outline the methods and the sequence of events, to encourage students to read the laboratory manual more carefully and to promote students' confidence in the subject. Consequently, this paper reports on the introduction of the online pre-laboratory exercises with respect to students' appreciation and interpretation of the chemical diagrams used in the exercises. Diagrams and illustrations are universally accepted as beneficial learning tools in many disciplines (Stieff, Bateman, \& Uttal, 2005). The pedagogical value of diagrams can be considered with respect to the characteristic, purpose and use of the diagram.

A chemical diagram is a representation in one or more of a multitude of forms such as a schematic, illustrative or symbolic representation. Scientific diagrams are generally labelled diagrams, often drawn to a scale, providing an accurate 
representation. The significant characteristics of chemical diagrams are in the visual impact provided by both the macroscopic and sub-microscopic levels. The visual impact of diagrams can enhance the development of mental models and lead to more connectedness in learning (Fiorea, Cuevasa, \& Oser, 2003). A chemical diagram can have one or more of a multitude of purposes, namely for explanation, description, instruction and to provide a mental picture. A multi-modal approach provides learners with the opportunity to synthesize their own mental model.

The value of a diagram in making the link with an abstract concept depends on it being consistent with the learners' needs and being pitched at the learners' level of understanding (Giordan, 1991). Gobert and Clement (1999) suggest that diagrams can have more than illustrative purposes, expanding the purpose of diagrams to model construction and reasoning. In this way, chemical diagrams serve as significant teaching tools; however, the value depends on the students' understanding of the diagram.

While the characteristics and purpose of diagrams are important, the way the diagram is used in the instruction is equally important. Flow charts, Venn diagrams, Vee-diagrams and concept maps are examples of diagrams in which students diagrammatically represent their understanding (Davidowitz \& Rollnick, 2003; Novak, 1990; Novak \& Gowin, 1984). These diagrams are pedagogically powerful because students have to actively construct the representation of their understanding and strategies for using these active diagrams are well documented (Davidowitz \& Rollnick, 2003; Novak, 1990; Novak \& Gowin, 1984). By contrast, diagrams of laboratory equipment are passive diagrams, presenting information to students. These traditional diagrams are consistent with transmission-style pedagogy when it is assumed that no specific strategy is needed to ensure student understanding. 
Chemistry is unique because of its dual characteristics: the real and visible characteristics of the macroscopic level and the real and "invisible" characteristics of the sub-microscopic level. The sub-microscopic level is as real as the macroscopic level - it is only the scale that distinguishes it, and the fact that the sub-microscopic level cannot be seen makes it hard to accept as real. Because these students were found to have poor mental models of the sub-microscopic level of matter (Chittleborough, Treagust, \& Mocerino, 2002), the addition of visual stimulus was provided to enhance students' ability to construct their own mental model. Consequently, chemical diagrams at the macroscopic and sub-microscopic level were intentionally included so that students experienced a variety of chemical diagrams.

Quality representations can promote engagement and motivation, but understanding is dependent on the user being able to map the target and the representation inherent in the visual, relating to previous knowledge and being cognisant of the metaphors that are being used (Skamp, 1996).

Chemists are now able to observe atoms or molecules, using an electron microscope; however it is not possible to see how the atoms interact. For these interactions, chemists rely on theories and in turn develop and utilise models that reveal and describe the theory. When "envisaging" an atom, chemists and students alike are picturing a model of an atom or a number of pictures of atoms based on various models (Taber, 2003). In this way, chemical diagrams play a very important role in describing the models that are used to represent chemical matter.

Johnstone $(1982 ; 1993)$ distinguished three levels of chemical representation of matter: the macroscopic level - the visible chemicals, the sub-microscopic level the particulate level and the symbolic level - including diagrams. Explanations of chemical phenomena usually rely on the behaviour of the sub-microscopic particles. 
Johnstone (1982) describes the macroscopic level as descriptive and functional, and the sub-microscopic level as representational and explanatory. Chemical diagrams commonly represent both the macroscopic and sub-microscopic representations, and therefore it is relevant to investigate students understanding of both levels of representation. The term visualisation is used extensively in chemical education research because of the need to provide a visual link to the abstract particulate nature of matter (Balaban, 1999). The sub-microscopic level cannot be seen but it is an essential component of chemistry and in order to teach about it, representations such as chemical diagrams are utilised to achieve this. An explanatory tool such as a diagram or an image can provide the learner with a way of visualising the concept and hence developing a mental model for the concept (Gabel, 1998).

A chemical diagram can include one or more levels of representation of matter: for example, a chemical diagram of distillation equipment, includes chemicals represented at the macroscopic level such as a liquid in the flask, and a diagram of a structural formula for a compound is a symbolic representation of the submicroscopic level of matter. Gilbert proposes that using visual representations, such as chemical diagrams, involves more than forming a mental image but rather involves metacognition, requiring the learner to navigate through multiple images, make assessments and interpretations of images. This skill Gilbert (2005) refers to as metavisualisation that is "metacognition in respect of visualisation" (p. 15). Because students' visualisation skills and their metavisual capacity impact on their learning, these need to be considered in pedagogical approaches (Kozma \& Russell (2005) This concept of visual literacy is important for learning. Gilbert (2005) points out the need for students to be aware of the conventions of diagrammatic representations and the scope and limitations of each diagrammatic mode. 


\section{Objective of the Study}

The overall objective of the research was to improve the learning situation for non major chemistry students with weak chemistry backgrounds by introducing chemical diagrams into the pre-laboratory exercises. This study investigated two research questions: What are students' understandings of chemical diagrams? and, How do students' understandings of chemical diagrams influence their understanding of chemical concepts? The desired outcome was for students to be better prepared for laboratory sessions and improve their ability to understand experiments. By making students use diagrams in an active manner - that requires interpretation - students' should become more familiar with diagrams and their understandings of chemical diagrams should be improved. These outcomes are dependent on the diagrams being beneficial learning tools and on the students being able to fully understand the diagrams.

\section{Methodology}

The university students involved in this study are generally "interested in their own learning, displaying qualities such as being discerning, pragmatic, critical and analytical in their attitude towards their learning" (Chittleborough, Treagust, \& Mocerino, 2005 p. 19). While their knowledge of chemistry is generally limited, their knowledge of the role of generic diagrams in the process of learning is typical of experienced learners (Chittleborough et al., 2005). This degree of knowledge is relevant to their responses to questions about the role of diagrams of chemical equipment for their learning of chemistry (Bransford, Brown, \& Cocking, 2000).

\section{Design}


When designing the pre-laboratory exercises, chemical diagrams were intentionally included to provide learners with visual tools to help students become familiar with laboratory equipment related to the weekly experiments and enhance explanations of chemical concepts. Chemical diagrams of the sub-microscopic level of matter were included to help students develop a mental model of the submicroscopic level of matter. Students primarily used the laboratory notes and course notebook which were printed by the university in an economical format - black and white print with very few diagrams. This meant that students did not use many diagrams. However, colour diagrams of the macroscopic and sub-microscopic levels of chemical representation displaying chemical equipment and chemical explanations were included in the online pre-laboratory exercises. The exercises required the students to make an interpretation using the diagram.

In this study, an intervention program was introduced whereby students had to complete online pre-laboratory exercises before each of the 11 laboratory classes. In designing the pre-laboratory exercises, chemical diagrams of the laboratory equipment were included with the aim of improving familiarity with equipment, understanding how the equipment functioned and improving the explanations of chemical phenomena. Students were required to interpret diagrams in order to complete the exercises using online pre-laboratory exercises that provided immediate feedback on their response and an opportunity to redo the exercise if their response was incorrect. The students performed experiments that commonly used equipment that was portrayed in the diagrams.

Students' ability to understand and learn chemistry was constrained by a lack of mental model of the sub-microscopic level of matter, their prior knowledge of chemistry, the assessment style of the course, the small number of chemical 
representations encountered by the student, the large amount of content, the speed with which the chemistry content had to be assimilated by the learner and a lack of motivation by the student to understand chemistry at a deeper level (Chittleborough et al., 2002). Students intentions were commonly to pass this course, a compulsory component of their science degree; not necessarily having a desire or high motivation to learn chemistry. In meeting the needs of this cohort of students pedagogical changes were made in order to create a more interactive learning environment that provided greater visual stimulus and better explanations. To this end, weekly compulsory on-line pre-laboratory exercises were introduced to better prepare students for the weekly experiment and provide basic information for students with little or no chemical background.

Students were required to access, complete and submit their answers to the pre-laboratory exercises electronically prior to the laboratory class each week. The exercises were deliberately designed to be straightforward and uncomplicated, endeavouring to help the students understand the practical and theoretical aspects of the experiment and to provide positive feedback.

The online pre-laboratory exercises were designed to take approximately 1020 minutes per week to complete and were worth $2 \%$ of the students' total marks. Even though the value of the task is very small, it was compulsory and designed to be a learning opportunity rather than an assessable task. Each week, there were on average about eight questions of varying formats including multiple-choice, shortanswer or matching. The web-based assessment provided students with immediate feedback. The correct answers were positively reinforced and for incorrect answers hints were given to help students identify any misconceptions. The desired outcomes 
of this project were to improve links between theory and practical work and provide immediate feedback to students.

\section{Participants}

This study involved university students undertaking a non-major chemistry course while enrolled in degree courses such as Environmental Biology, Health Sciences, Human Biology, and Environmental Health. Of the 122 students enrolled in the introductory first-year university chemistry course, 17 students volunteered to be interviewed about the chemical diagrams. The selection was not random; rather volunteers were invited to participate. This interview sample group of six (35\%) males and $11(65 \%)$ females included more females than were representative in the enrolled population of $46 \%$ males and $54 \%$ females. The age range of the interview group comprised eight students who had attended high school the previous year and nine who attended school from two to 15 years ago. The age range of the enrolled students is not available. The academic ability of the interview groups was not ascertained, however all students taking this unit had limited or no chemical background knowledge.

The tuition for the course consists of a one-hour lecture and a three-hour laboratory session per week. The students are motivated to pass the course because it is a compulsory component of the degree course, but they generally do not continue with chemistry after first year and it is not their major area of study. Characteristically, students entering this course have weak background knowledge in mathematics and chemistry (Chittleborough et al., 2002).

\section{The Chemical Diagrams}

Diagrams were intentionally used in the pre-laboratory exercises to help with identification of chemical apparatus and promote understanding. A summary of the 
characteristics of each of the chemical diagrams investigated in this study is provided in Table 1 including purpose, level of representation, explanatory function and the relevant mental model to which the various diagrams relate.

\section{Place Table 1 about here}

\section{Data Sources}

\section{Enrolled Sstudents}

The mean, standard deviation and item discrimination values for all the enrolled students' responses to exercises that include chemical diagrams from the weekly online pre-laboratory exercises $(n=122)$. The Item discrimination refers to the ability of an item to differentiate among students on the basis of their responses. The item discrimination index is a correlation between student responses to a particular item and total scores on all other items on the weekly exercises. Item discrimination is "good" if the index is above .30; "fair" if it is between .10 and .30; and "poor" if it is below .10. For most questions the item discrimination values were good.

\section{Volunteer Students}

The volunteer students were interviewed in two series - after week 5 and week 12 of the 12-week semester about their understanding of chemical diagrams from the pre-laboratory exercises. The interviews for the first series $(n=15)$ were conducted individually ( $\mathrm{n}=5)$ and in groups, depending on students' availability (3 pairs and one group of four). The interviews for the second series questioned students about diagrams from weeks 6-11. This smaller group of five students had some of the same students from the first series but some different students. Some students were more comfortable being interviewed in a group situation and there is evidence from the data that they listened and learnt from each other during the interview. With group interviews, the interviewer attempted to elicit each student's opinions through 
directed questioning. Each interview took approximately one hour. In the interview, students were asked to relate the diagrams to their laboratory experience, for example: What does the diagram show? What is happening to the mixture in the distilling flask? Has the image supported what you already know?

The number of students completing the first series of interviews fluctuated from 15 to 17 with pressures of time and other commitments. In reporting the results pseudonyms are used. The transcripts were coded using N-Vivo in terms of relevant aspects of students' understanding. An associate acted as an independent researcher (Merriam, 1998) crosschecking the coded categories and the coded text to verify coding accuracy.

\section{Analysis}

The data for the enrolled students were considered alongside the interview data from the volunteers when making inferences and drawing conclusions; however, the generalisability of the data was limited due to the small size of the interview sample and the variation within the interview sample compared with that of the enrolled class.

The analysis was based on multiple student responses to a variety of types of diagrammatic representations (see Table 1)(Chittleborough, 2004). Direct and indirect questions were used to delve into students' understanding of both the chemical content and their learning. The interview responses provided data about the students' perspective of their understanding of the chemical content and of the way they were interpreting and using the diagram to learn. All interviews were conducted by the first author, providing reliability to the quantitative data collection. Similarly, the analysis was conducted primarily by the first author, with crosschecking by associates to reduce the influence of any biases. 


\section{Results}

Selected representative research data are presented to respond to the research questions: What are students' understandings of chemical diagrams, and How does students' understandings of chemical diagrams influence their understanding of chemical concepts? Both research questions are addressed simultaneously assuming that if students better understand the chemical drawing then their understanding of the chemical concept will also be better. The results of the data analysis are presented in terms of assertions (Erickson, 1998).

-There was a large variation in students' level of understanding of the chemical diagrams even within the small interview sample group. This was unexpected and was attributed to the weak background knowledge of the student, unfamiliarity with the nature of chemical drawings and the lack of practice in interpreting chemical diagrams.

Four assertions have been drawn from the data.

Assertion 1 All students interviewed appreciated that chemical diagrams contained information that was useful for purposes such as setting up laboratory equipment and for explaining particular chemical phenomena.

Assertion 2 Students' level of understanding of a chemical diagram varied greatly.

Assertion 3 The connections between the diagrams of the macroscopic level (equipment), the sub-microscopic level (molecular) and the symbolic level (equations) are not always apparent to students.

Assertion 4 Chemical diagrams can introduce misconceptions of chemical concepts. 
To illustrate students' understanding and support for the assertions, data for five of the possible twelve chemical diagrams are presented. The diagrams show macroscopic, sub-microscopic and symbolic representations. They illustrate relevant assertions of all the diagrams as shown in Table 1. Data from each diagram was selected to best illustrate the assertions and consequently there is not an even distribution of data from each of the five diagrams. The relevant assertion number is shown in brackets adjacent to the supporting data.

\section{Distillation Diagram}

\section{Place Table 2 and Figure 1 about here}

Student responses to the four questions in the pre-laboratory exercises about the distillation diagram (see Figure 1) are shown in Table 2. Not surprisingly all students interviewed $(17 / 17,100 \%)$ agreed that the distillation diagram was useful in helping them setup equipment in the laboratory (Assertion 1). Despite this, some students $(5 / 17,29 \%)$ could not explain the workings of a condenser even though they had performed the experiment using the equipment in the diagram and answered questions using the diagram (Assertion 2). For example

Int.: Where does the water go in and out?

Alice: In there, [pointing to the water-in tube in the diagram] And then it came out the top bit? Didn't it? Did it?

Int: What was the point of this condenser here? Do you remember what it does?

Alice: Um. Not really.

Int.: And the water in, the water from the tap, did that water mix up with this mixture in the distilling flask?

Alice: No, I don't think so. Did it? I don't know. I don't think so

This result is confirmed by the low results from the enrolled students to question 2 with $46.7 \%$ correctly describing how the water flow through the condenser (Table 2).

Generally students' descriptions referred to the macroscopic level, which is consistent with the diagram and their experience. Some students' $(4 / 17,23 \%)$ had very poor knowledge of basic chemical terminology including the names of apparatus 
and changes of state. This is demonstrated in their responses, talking about evaporating liquid rather than boiling, referring to all liquids as water, and using the terms vapour and steam interchangeably (Assertions 2). For example:

Alice: The water turns everything into a vapour from his, and I don't really know.

Marc: It used to be like, steam or something.

One student pointed out that the distillation diagram is a replica of the apparatus:

Karen: It just tells you what each thing is. It doesn't actually tell you how it happens. Like I still don't grasp how one long tube is a condenser.

From the interviews and observations in the laboratory, differences were identified in what people 'see'. The macroscopic is what is visible, and the submicroscopic view is envisioned spontaneously by experienced learners, familiar with the particulate nature of matter. Learners who are not familiar with the particulate nature of matter see the macroscopic chemicals and equipment. And as Karen pointed out, the diagram does not explain how the condenser works. For the experienced chemistry learner, the diagram included an implied explanation - one that is not necessarily visible, but is understood. For novices there is no explanation of how the distillation equipment works. All of the students confirmed that the diagram did not show the molecular level, and it did not help them understand the molecular level (Assertion 3). So even though the students here have described the diagram, the level at which they comprehended the diagram limits its effectiveness. In order to explain the process of distillation, the sub-microscopic movements need to be included.

\section{Fractionating Column Diagram}

Figure 2 prompted students to examine how the fractionating column operated by examining the molecules of the three different liquids, $\mathrm{A}, \mathrm{B} \& \mathrm{C}$, present in the mixture. The diagram included a written explanation that students could read to help 
them understand the process. The results to the questions in the pre-laboratory exercises are shown in Table 3.

\section{Place Table 3 and Figure 2 about here}

During the interviews only a minority of the students $(4 / 17,24 \%)$ expressed a clear understanding of the workings of the fractionating column diagram (Assertion 2). When asked "What is happening to the mixture in the fractionating column at the molecular level?" the responses revealed a lack of understanding, for example:

Karen: Well, as the temperature's decreasing, molecules with less efficiency, I suppose are reaching the top.

Karen used everyday terminology i.e. efficiency and associated it with temperature.

Betty: l'd probably say that these ones [referring to A] are smaller because these ones [referring to $C$ ] are too heavy-. Because as it cools, they condense, and just fall back down to the bottom, but these ones [referring to A] aren't, so they continue up.

Despite the diagram showing A, B and C as the same size circle, Betty associated size and weight with the progression of molecule A up the column. However, at the same time Betty appeared to appreciate that condensation is a factor of temperature.

Sue: $\quad$ Maybe when they hit the certain temperature, it causes them to not fractionally distillate?

Sue looked for a fact or property to explain the diagram.

The interview responses highlight the inability of some students to talk about chemistry, revealing a poor chemical vocabulary and a shallow understanding of the changes of state $(6 / 17,35 \%)$ occurring in the fractionating column (Assertion 2). A common misconception of associating mass and weight with the boiling point was evident in this excerpt:

Int.: What state are they in here in the column?

Jen: $\quad$ They're below the boiling point. I don't know.

Int.: $\quad$ So what do you think is happening? Why are some of them turning round and going back down the other way?

Carol: $\quad$ They're too heavy. 
Int: $\quad$ They're too heavy?

Carol: $\quad$ Too dense.

Int.: What changes in the column as the molecules are going up the column?

Jen: $\quad$ The temperature decreases.

Int.: $\quad$ So what's the effect of that decrease in temperature?

Jen: It would cause them to become more solid. Whatever the stuff was. So then, like Carol said, when they get too heavy they fall back down.

The comment above shows how the diagram may have caused a misconception of mass influencing the change of state by students associating the movement in the column with the effect of gravity (Assertion 4).

Beginning at a high temperature, the fractional distillation equipment vapourises all components and then separates them on the basis of the temperature at which they condense back to a liquid. Many students clung to the idea of starting at the liquid phase and converting to a vapour. Bob and Ned are typical of the interview conversations and their responses are used here to demonstrate that the students had some correct ideas mixed with some misinterpretations and that they changed their ideas after interpreting the diagram more critically during the interview.

Ned: It just shows that the different points are the different temperatures, and which, um, some of the substances are going to be, what do you call it, fractionated?

Bob: Yeah, no, yeah, just clearly shows that $A$ will actually go all the way through but $B$ and $C$ won't.

These descriptions were from cursory inspections of the diagram and did not include a description at the sub-microscopic level.

Ned: A has got the lowest boiling point. So $C$, when it's introduced, pretty much stays where it is, because of its boiling point. B goes up, comes out there. A goes out the top.

Bob: B actually stays in the beads, or whatever, and it travels back down to the base.

Int:: Why does it fall down there?

Ned: It has to wait until all of $A$ has been expelled? Is that right?

Int:: Hm. That's a good question. What do you think?

Bob: I think just wait 'til the actual temperature's high enough. Like when you get to that point, the temperature should be high enough to keep it going up.

Int.: High enough?

Bob: Yeah, so like the temperatures high enough.

Ned: Oh, yeah, because the... 
Bob: To get it to there, but the temperatures of it is too low to keep it as a gas, so it travels back down. So as long as you keep it going towards the temperature, gets higher, the further up the column it goes.

Int.: Okay. What do you think Ned? -.

Ned: Essentially it is that it gets up to temperature, and then stays at a constant temperature until all of $A$ has been expelled from it, and then it will go down into $B$.

Int:: Okay.

Bob: We had to wait for those-

Ned: And then it will go down to C, but I'm not-.

Bob: The temperature range at the top of the beads, to reach the actual boiling point for the liquid, and then it will actually escape the beads.

Misconceptions included misinterpreting the temperature scale and confusing temperature and heat (Assertion 4). That the temperature scale on the diagram has lower values as the molecules go higher was counterintuitive and unexpected for many students, causing misinterpretation of the diagram. The discussion through the interview sometimes clarified the students' understanding.

Int.: $\quad$ So what happens - as you're going up the column, what's happening to the temperature?

Bob: $\quad$ The temperature drops.

Int: $\quad$ Why?

Bob: $\quad$ The heat source is at the bottom.

Int.: $\quad$ So what happens here at $140^{\circ} \mathrm{C}$ ?

Bob: $\quad$ Well $\mathrm{C}$ will turn back to a liquid because it's-

Ned: $\quad$ So it actually travels back down again.

Bob: $\quad$ Because it's no longer a vapour, it's actually started to liquefy and go back down.

Int: $\quad$ Why does it liquefy?

Bob: $\quad$ Because the temperature's gone under the boiling point.

Int: $\quad$ Okay. What happens to B then?

Ned: $\quad$ B goes back down because it hasn't reached the yeah.

Bob: $\quad$ The temperature ..... boiling.

Int.: $\quad$ Okay. So same thing. And what about A?

Ned: $\quad$ A's got enough, so it's expelled. It's been boiled so it stays vapour and gone out

Int.: $\quad$ At $102^{\circ} \mathrm{C}$ here, is it still going to be in one state.

Ned: It's still going to be a gas. 
Bob:

It's still a vapour, yeah.

Bob has connected the temperature with the boiling point and the change of state. The dialogue demonstrated that Ned and Bob were deciphering what the diagram was trying to say - being dissatisfied with their initial interpretation, and eventually, through some prompting by the interviewer and discussion, being able to explain what was happening at the molecular level and why it was happening (Assertion 3). Indeed, the interviews revealed that students were able to answer the questions on the prelaboratory exercises (Table 3) correctly without really understanding the diagram, identifying the poor design of the questions.

Bob and Ned drew on their laboratory experience when discussing the diagram as did Caz in the following excerpt from her interview.

Int.: You could actually see something going on?

Caz: Yeah, you could see it condense and run back down.

Doug, a mature-age student, commented on his approach with the fractionating column diagram.

Doug: It took me a couple of minutes looking at it with the questions there, the A, B and C thing, there. It actually made me think about what was happening temperature-wise in the fraction column, as compared to the boiling point of the material.

Explaining the distillation process in detail required thinking at the sub-microscopic level and the macroscopic level simultaneously and this could explain why the fractional distillation process proved to be difficult for students to grasp.

\section{Column Chromatography}

Nearly all the students interviewed $(13 / 15,87 \%)$ agreed that the diagram (Figure 3) was useful in explaining what was happening to the mixture in the chromatography column (Assertion 1).

Katrina: Yeah. I think it helped, 'cause having no idea about it, it definitely helped. It was a little bit difficult to understand at first. When I looked at it first I really didn't know what was going on in it. But yeah when you went into the lab and you saw what you had to do, then 
you could figure out how to relate it back to the picture.

Because the diagram was not identical to the equipment actually used in the laboratory, some students interviewed considered that it was not as useful in helping them set up equipment in the laboratory. The data indicates that nearly all the interviewed students $(n=15)$ distinguished diagrams that illustrate the experimental setup from those which describe and explain the concept. Doug's comment about Figure 3 indicated his ability to recognise the purpose of a diagram.

Doug: I find diagrams that actually show the set up of the equipment we are going to use in the lab far more instructional than conceptual diagrams, if you like. And I would regard that [Figure 3] as a conceptual diagram, whereas where it came to actually setting up the lab equipment, I think a lot of people were having the problem of that, having to extrapolate and saying what we do with this.

Students' understanding of the chemistry underlying the column chromatography varied (Assertion 2). Some students $(5 / 17,29 \%)$ regarded the size of the molecule to be the determining factor in its movement through the column. Only three of the students interviewed $(3 / 17,18 \%)$ were able to describe correctly the movement of molecules through the column (Assertion 3). The low number of correct responses by the interviewed students contrast with the high number of correct responses by the enrolled students $(n=122)$. Table 4 shows that $86 \%$ of students were able to select the correct response to identifying the aim of the column chromatography experiment. Only 55\% were able to correctly identify "Which component will move through the column most quickly?" but this item has a poor item discrimination value and a corresponding high standard deviation.

Students abilities to discuss the experiment and explain the process varied as illustrated in these responses during the interviews:

Doug: the movement of the solvent is dependent on its binding to the material packed in the column 
Bobby: because of the size of the particles with the alumina and whatever, they travelled through like, because it got, like there was the purple, yellow, you know different sizes, so that one travels through faster.

Kenny: I think it shows, because the mixture's got lots of different substances, so it kind of separates the substances, because each substance has a different solubility. So it's different rates, so this picture shows that collecting things that's been timed. So kind of demonstrates how a solvent has a mixture and the column separates each mixture.

Students' commonly used limited and everyday vocabulary in explaining the experiment, after doing pre-laboratory exercises and conducting the experiment.

Place Table 4 and Figure 3 about here

\section{Chemical Equilibrium}

Place Table 5 and Figure 4 about here

Interview data confirmed that all students found Figure 4 helpful in understanding the procedure of the experiment (Assertion 1). The percentage of correct responses to questions 3 and 4 in the pre-laboratory online exercises (see Table 5), requiring students to identify the chemical species were poor. Similarly, the interview data showed that some students $(10 / 17,59 \%)$ had difficulty understanding the chemicals they started and ended with and were often confused about the species - iodine, iodide ion and tri-iodide ion - and the medium (Assertion 2). Many students $(9 / 16,56 \%)$ were not able to relate the equations to the macroscopic diagrams during the interviews. The symbols and equations for the chemicals were drawn onto Figure 4 as part of the interview. In this way symbols and equations relating to the submicroscopic level were transposed onto the drawing of the macroscopic level (Assertion 3). 
Misunderstandings included students assuming that the equilibrium was only occurring at the interface; another student inferred that the two immiscible layers in the flask corresponded to the numerator and denominator of the equilibrium constant. Students were drawn to the prominent macroscopic physical feature of the two immiscible layers because they could see it and assumed that this was a manifestation of the equilibrium situation. Other students interpreted the two separate layers as meaning that no reaction was occurring because the solutions did not mix (Assertion 4).

\section{Structural Formulas}

Chemical diagrams include structural formula representations. Those students with limited background knowledge in chemistry did not easily connect alternative symbolic representations of the same molecule. For example, molecular and structural formulas were frequently not identified by students to be the same compound simply because they looked different. Students were asked about the diagram of a triglyceride ester (Figure 5) and when interviewed were not in the habit of drawing out the molecular formulas to show the structural formulas. Consequently, some did not easily identify the carbonyl group. The data for the enrolled students indicates $77 \%$ of students were able to identify the triglyceride ester. The interview data revealed that students worked out the answer through a process of elimination.-

\section{Insert Table 6 and Figure 5 about here}

Students' comments show how they had to learn to use the diagrams:

Gina: I probably would have noticed if l'd drawn it out, but um, l've done it - I'm not in the habit of drawing them out.

Rae: Yeah, I just used to, like put in, l'd put in triglyceride ester (into an internet search) and it would come up with all these different sites and I just go into the ones that....

Int.: Okay. So do you understand what that formula there for say B would mean? 
Rae: Yeah, I actually draw them out like that [referring to a expanded structural formula] in the tests because I understand them better, than that.

To experienced chemists the structural formula is self-evident from the molecular formula; however, with these students, with very little experience, it is not. For the common hydrocarbon families, the Silberberg (2000) textbook provided spatial and structural formula as well as common uses. These diagrams were used in the prelaboratory exercises for aldehydes and ketones, carboxylic acids and amide molecules. These diagrams highlighted the common group and provided multiple representations and terminology of the compounds, showing the structural and spatial representations. The students interviewed $(n=5)$ considered these representations to be useful to varying degrees (Assertion 2).

Gina: Yes, because it reinforces then, the point you're actually trying to make. And the other thing is that some people see things in different ways. See, I wouldn't look at that alone. But the three together [spatial, structural and text] was good.

Rae: That means nothing to me. [referring to the spatial representation]

Rae did not relate to the sub-microscopic level, using the symbolic level and the macroscopic level only (Assertion 3). Initially the diagrams were introduced into the pre-laboratory exercises to provide learners with visual tools to enhance explanations. From the data it would be mistaken to assume that all students fully understand the chemical diagrams. However, overall the students did benefit from the inclusion of diagrams; with diagrams at the macroscopic level more easily understood than those at the sub-microscopic level. Students appreciated the variety of purposes that a diagram can have including illustrative, instructional, descriptive and explanatory.

Students' interview responses revealed limitations in several skills that are advantageous to develop when learning chemistry:

- A lack of ability to "picture" or talk about the sub-microscopic level. This influenced their ability to interpret diagrams at the sub- 
microscopic level. It is not surprising that students with limited chemical background commonly interpret the chemical diagrams at a macroscopic level seeing only the laboratory equipment. To envision the sub-microscopic level that could enable students to better explain the chemical phenomena, e.g. Alice was not confident in explaining how the condenser worked in the distillation equipment.

- A lack of ability to attend to the detail of the diagram. Commonly throughout the interviews students were challenged to interpret diagrams more critically, e.g. Bob and Ned interpreting the temperature scale.

- A lack of ability to use chemical terminology accurately. The students' verbal responses that used everyday language and chemical phrases carelessly contrasted with the precise and limited nature of chemical vocabulary with which many of these students were not familiar.

The study has highlighted difficulties for students with little or no chemical background knowledge who have not had the opportunity to develop these necessary skills. It seems evident that visual aids such as chemical diagrams should be used in conjunction with rich verbal and written forms to tackle this issue.

Chemical diagrams should suit the intended purpose. So for setting up laboratory equipment a diagram that accurately portrays the actual laboratory equipment would be recommended. This may help students better understand the physical set-up of the experiment at the macroscopic level but it may not help them to understand the changes that are occurring at the sub-microscopic level. For explanatory purpose, diagrams which relate the levels of chemical representation or the particular concept would be recommended. 
Throughout the interviews, additional inscriptions on the diagrams proved to be beneficial to students' understanding. Using the complementary diagrams of the macroscopic, sub-microscopic and symbolic levels of representation as was done with the equilibrium diagram and relating them to experimental experience is supportive of the conclusions by Bowen and Roth that "inscriptions are something "everyone uses" (2002 p. 324). These complementary diagrams reinforced the idea of connecting both the macroscopic and the symbolic diagrams that aided understanding of the submicroscopic level.

The results of this study could be used to inform pedagogical content knowledge about teaching with chemical diagrams. The results of this study indicated that students did not always interpret diagrams correctly, even though they did answer online pre-laboratory questions on the diagrams, suggesting that there is a need for strategies that would promote active interaction with diagrams. Consistent with a constructivist approach, these suggested strategies require the student to demonstrate their understanding and receive feedback. In this way, the diagram becomes an active tool rather than a passive tool for learning.

The results of this study confirm the research literature claims of the importance of visualisation tools in learning. This research adds to the current research by identifying the importance of drawings in promoting an understanding of the sub-microscopic level of matter by helping students to develop personal mental models of that level. The data showed that some students did not interpret or use the diagrams correctly and highlighted the importance of students actively using diagrams and having the necessary skills to use and interpret chemical diagrams correctly. In this way, the data support Gilbert's notion of metavisualisation and the need to use diagrams actively and metacogitively. 


\section{Conclusions}

The data presented have addressed the research questions: What are students' understandings of chemical diagrams? And, How does students' understandings of chemical diagrams influence their understanding of chemical concepts. The research has shown that the 17 interviewed students reported that chemical diagrams are useful for purposes such as presenting and describing laboratory equipment and explaining particular chemical phenomena (Assertion 1); however, from this research it was clear that students' understanding of a chemical diagram cannot be assured (Assertion 2). While all the students appreciated that chemical diagrams are useful to visualise the submicroscopic or molecular level, not all students were at ease using this level of representation. For students with little or no chemical background knowledge, diagrams of the sub-microscopic level of representation appeared more difficult to interpret. The value of chemical diagrams was demonstrated in their ability to connect ideas and concepts, particularly connecting the macroscopic and the sub-microscopic levels of representation (Assertion 3). However, students' interpretations of chemical diagrams can introduce misconceptions in their understanding (Assertion 4). The low levels of understanding of simple diagrams were surprising and would suggest that the assumed level of understanding is higher than that which actually occurs. Visualisation tools are accepted as sound educational resources; however, despite this, the result of this study highlight the importance of the way that diagrams are used in order to be effective teaching resources.

The introduction of diagrams in the pre-laboratory exercises was intended to benefit learning. The results provide evidence that they did, however there was also evidence that not all students understood the diagrams as well as was assumed. There are implications here for the pedagogical use of chemical diagrams. Commonly, 
students' understanding of diagrams improved as a result of the interviews indicating that the questioning and resulting discussion about the diagrams increased their levels of understanding. The diagrams are powerful explanatory tools that can contribute to learning when used in a constructive manner. By improving the way teachers and students use chemical diagrams, the links between the various levels of chemical representation could be improved.

\section{Bibliography}

Balaban, A. T. (1999). Visual chemistry: Three-dimensional perception of chemical structures. Journal of Science Education and Technology, 8(4), 251-255.

Bowen, G. M., \& Roth, W. M. (2002). Why students may not learn to interpret scientific inscriptions. Research in Science Education, 32(3), 303-327.

Bransford, J. D., Brown, A. L., \& Cocking, R. R. (2000). How people learn: Brain, mind, experience, and school. Washington DC: National Academy Press.

Chittleborough, G. D. (2004). The role of teaching models and chemical representations in developing students' mental models of chemical phenomena. Unpublished doctoral thesis, from http://adt.curtin.edu.au/theses/available/adt-WCU20041112.125243/

Chittleborough, G. D., Treagust, D. F., \& Mocerino, M. (2002). Constraints to the development of first year university chemistry students' mental models of chemical phenomena. In A. Bunker \& G. Swan (Eds.), Focusing on the student (pp. 43-50). Perth, WA: Professional Development@Learning Development Services.

Chittleborough, G. D., Treagust, D. F., \& Mocerino, M. (2005). Non-major chemistry students' learning strategies: Explaining their choice and examining the implications for teaching and learning. Science Education International, 16(1), 5-21.

Davidowitz, B., \& Rollnick, M. (2003). Enabling metacognition in the laboratory:A case study of four second year university chemistry students. Research in Science Education, 33(1), 43-69.

Denial, M. (1987). Chemistry. London: Pan Books Pty Ltd.

Erickson, F. (1998). Qualitative research methods for science education. In B. J. Fraser \& K. Tobin (Eds.), International handbook of science education (pp. 1155-1173). Dordrecht, The Netherlands: Kluwer.

Fiorea, S. M., Cuevasa, H. M., \& Oser, R. L. (2003). A picture is worth a thousand connections: The facilitative effects of diagrams on mental model development and task performance. Computers in Human Behavior, 19(2), 185-199. 
Gabel, D. (1998). The complexity of chemistry and implications for teaching. In B. Fraser \& K. Tobin (Eds.), International handbook of science education (pp. 233-248). Dordrecht, The Netherlands: Kluwer Academic Publishers.

Gilbert, J. K. (2005). Visualization: A metacognitive skill in science education. In J. K. Gilbert (Ed.), Visualization in Science Education (pp. 9-27). Dordrecht, the Netherlands: Springer.

Giordan, A. (1991). The importance of modelling in the teaching and popularisation of science. Impact of Science on Society, 164, 321-338.

Gobert, J. D., \& Clement, J. J. (1999). Effects of student-generated diagrams versus student-generated summaries on conceptual understanding of causal and dynamic knowledge in plate tectonics. Journal of Research in Science Teaching, 36(1), 39-53.

Johnstone, A. H. (1982). Macro- and micro- chemistry. School Science Review, 64, 377-379.

Johnstone, A. H. (1993). The development of chemistry teaching: A changing response to changing demand. Journal of Chemical Education, 70(9), 701705 .

Kozma, R.-B., \& Russell, J. (2005). Students becoming chemists: developing representational competence. In J. K. Gilbert (Ed.), Visualization in Science Education (pp. 121-146). Dordrecht, the Netherlands: Springer.

Merriam, S. B. (1998). Qualitative research and case study applications in education. San Francisco CA: Jossey-Bass Publishers.

Novak, J. D. (1990). Concept mapping: A useful tool for science education. Journal of Research in Science Teaching, 27(10), 937-949.

Novak, J. D., \& Gowin, D. B. (1984). Learning how to learn. New York: Cambridge University Press.

Silberberg, M. S. (2000). Chemistry: The molecular nature of matter and change (2nd ed.). Boston: McGraw Hill.

Skamp, K. (1996). Elementary school chemistry: Has its potential been realized? School Science and Mathematics, 96(5), 247-254.

Stieff, M., Bateman, R. C. J., \& Uttal, D. H. (2005). Teaching and learning with threedimensional representations. In J. K. Gilbert (Ed.), Visualization in Science Education (pp. 93-120). Dordrecht, the Netherlands: Springer.

Taber, K. S. (2003). The atom in the chemistry curriclum: Fundamental concept, teaching model or epistemological obstacle? Foundations of Chemistry, 5, 4384. 
Table 2 Results for the online pre-laboratory questions relating to the distillation

$$
\text { diagram }(n=122)
$$

\begin{tabular}{llll}
\hline Question & $\begin{array}{l}\text { Discrim } \\
\text { ination }\end{array}$ & $\begin{array}{l}\text { Mean } \\
\%\end{array}$ & SD \\
\hline Q1 Matching the names with the meanings of the parts of the distillation & 0.47 & 83.5 & 28.2 \\
equipment & & & \\
Q2 How must the water flow through the condenser? & 0.56 & 46.7 & 50.1 \\
Q3 Why is a heating mantle used? & 0.36 & 63.1 & 48.4 \\
Q4 Where must the thermometer be placed in the distillation apparatus and & 0.51 & 76.2 & 42.7 \\
why? & & & \\
\hline
\end{tabular}


Table 3 Results for the online pre-laboratory questions relating to the fractionating

column $n=122$

\begin{tabular}{llll}
\hline Question & $\begin{array}{l}\text { Discrim } \\
\text { ination }\end{array}$ & $\begin{array}{l}\text { Mean } \\
\%\end{array}$ & SD \\
\hline Q1 Which liquid A, B, C, will be the first fraction? & 0.40 & 76.2 & 40.5 \\
Q2 What happens to the temperature in the column from the bottom to the & 0.51 & 79.5 & 43.2 \\
top? & & & \\
$\begin{array}{l}\text { Q3 Why do some substances condense back to a liquid in the fractionating } \\
\text { column? }\end{array}$ & 0.65 & 75.4 & 47.7 \\
\hline
\end{tabular}


Table 4 Results for the online pre-laboratory questions relating to the chromatography column $(n=122)$

\begin{tabular}{lccc}
\hline Question & $\begin{array}{c}\text { Discrim } \\
\text { ination }\end{array}$ & $\begin{array}{l}\text { Mean } \\
\%\end{array}$ & SD \\
\hline Q1 The aim of this experiment is to.... & 0.37 & $86.4 \%$ & 34.4 \\
Q2 Chromatography is a separation techniques based on differences in the & 0.54 & $76.0 \%$ & 42.9 \\
components: & 0.21 & $54.8 \%$ & 35.0 \\
Q3 Which component will move through the column most quickly? & &
\end{tabular}


Table 5 Results for the questions relating to the equilibrium $(n=122)$

\begin{tabular}{|c|c|c|c|}
\hline Question & $\begin{array}{l}\text { Discri } \\
\text { minati } \\
\text { on }\end{array}$ & $\begin{array}{l}\text { Mean } \\
\%\end{array}$ & SD \\
\hline Q1 Match the term with the correct meaning e.g. water; Immiscible; []; & 0.63 & $85.3 \%$ & 24.3 \\
\hline $\begin{array}{l}\text { Q2 Match the symbol with the correct meaning, e.g. org, } I_{3}^{-}, I_{2} \\
\text { Q3 There are two systems of varying concentration considered in this }\end{array}$ & 0.50 & $93.8 \%$ & 17.5 \\
\hline $\begin{array}{l}\text { experiment. The diagram outlines the method. What species are present in } \\
\text { the aqueous layer? }\end{array}$ & 0.49 & $50.4 \%$ & 50.2 \\
\hline Q4 What species are present in the organic layer? & 0.55 & $57.8 \%$ & 49.6 \\
\hline $\begin{array}{l}\text { Q5 The method recommends the use of a } 5 \mathrm{~mL} \text { dry pipette to measure out } \\
5 \mathrm{ml} \text { from the organic layer. This technique is important because: }\end{array}$ & 0.45 & $84.4 \%$ & 36.4 \\
\hline $\begin{array}{l}\text { Q6 The equilibrium constant for equilibrium system 1, in the aqueous layer } \\
\text { is: }\end{array}$ & 0.55 & $91.1 \%$ & 28.6 \\
\hline $\begin{array}{l}\text { Q7The equilibrium constant for equilibrium system 2, at the interface of the } \\
\text { organic and aqueous layer is: }\end{array}$ & 0.57 & $54.1 \%$ & 50 \\
\hline
\end{tabular}


Table 6 Results for the questions relating to the structural formulas- week 6 $(n=108)$

\begin{tabular}{lccc}
\hline Question & Discrimination & $\begin{array}{l}\text { Mean } \\
\%\end{array}$ & SD \\
\hline $\begin{array}{l}\text { Choose which of the structures represents a triglyceride ester (a } \\
\text { fat or oil) }\end{array}$ & 0.23 & $77.1 \%$ & 42.1 \\
\hline
\end{tabular}


Distillation

Martin S. Saborberg, Chemietry: The Molecular Nature of Matter and Change, $2^{\text {nd }}$ Edition. Copyright e The McGraw-Hill Companies, Inc. All righte roserved.

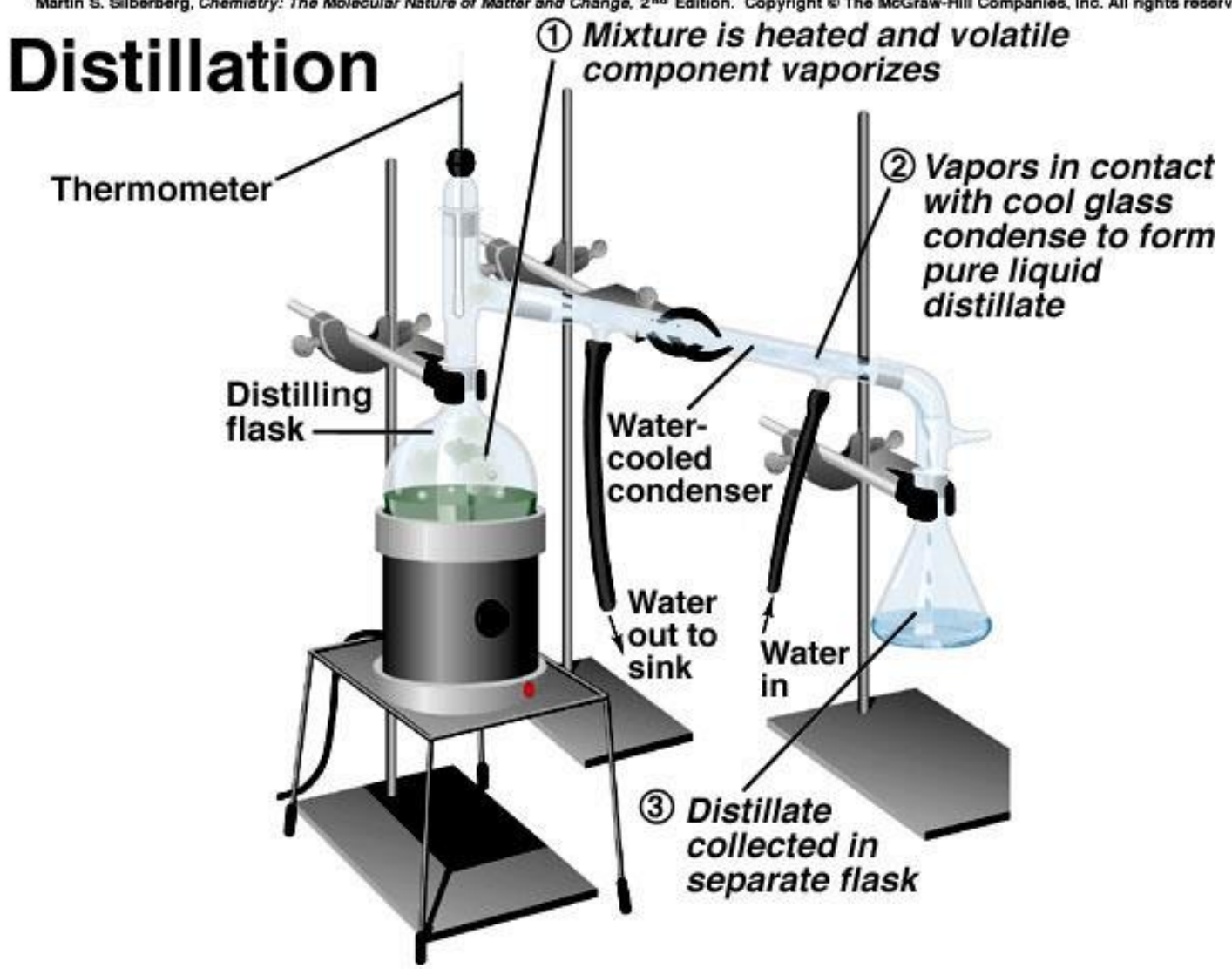

Figure 1 Distillation Column (Silberberg, 2000 p. 77) 


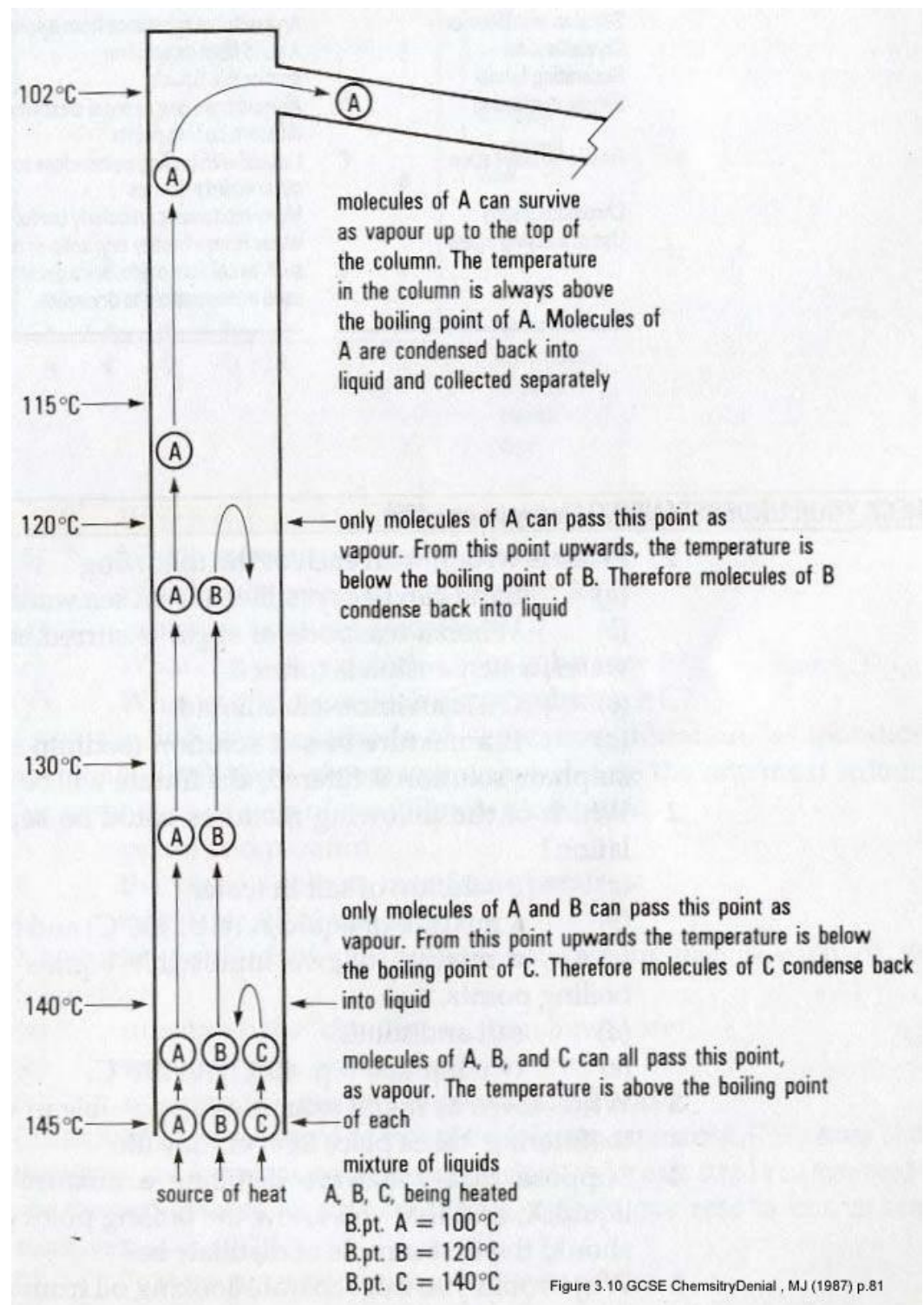

Figure 2 Fractional Distillation (Denial, 1987 p. 81) 


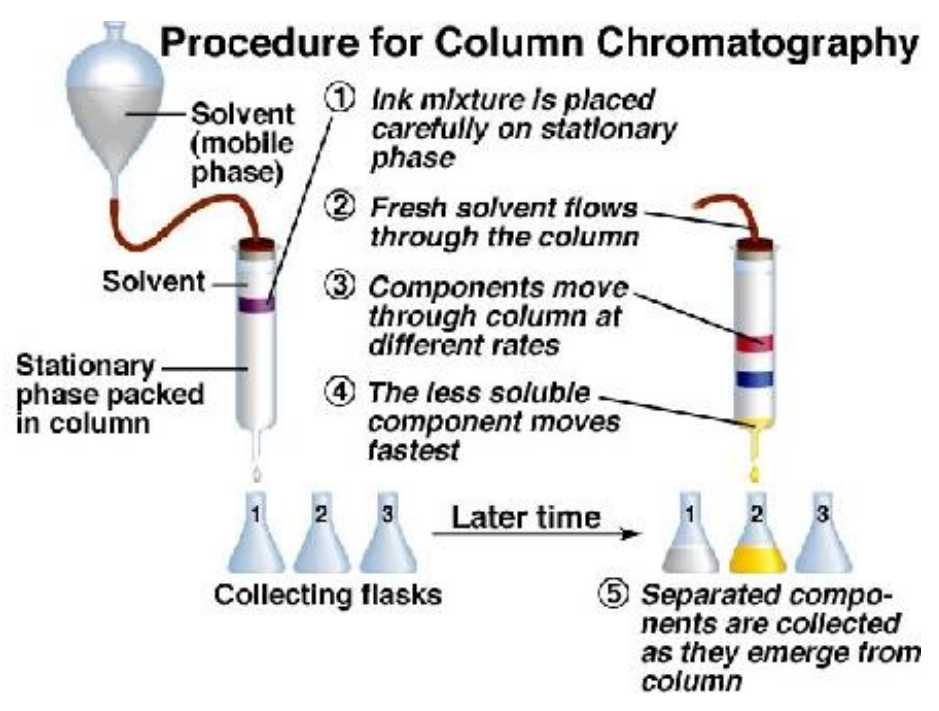

Figure 3 Column Chromatography (Silberberg, 2000 p. 78) 


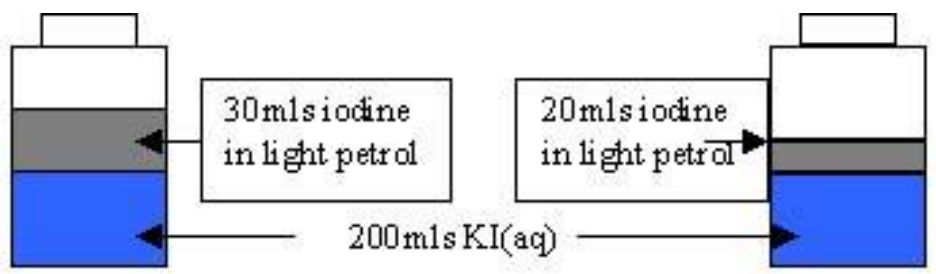

Shake each jar for 15 minutes

Identify two byers- aqueous and organic

For EACH jar -

$-p$ ipette $50 \mathrm{~mL}$ s aqueous layer and titrate with $0.02 \mathrm{M} \mathrm{Na} \mathrm{S}_{2} \mathrm{O}_{3}$

$-\mathrm{p}$ ipette $5 \mathrm{~mL} s$ organic layer and titrate with $0.002 \mathrm{M} \mathrm{Na} \mathrm{S}_{2} \mathrm{~S}_{2} \mathrm{O}_{3}$

Figure 4 Equilibrium Experiment 


\begin{tabular}{|c|c|}
\hline $\mathrm{CH}_{2} \mathrm{OH}$ & \\
\hline CHOH & $\mathrm{HO}_{2} \mathrm{CR}$ \\
\hline $\mathrm{CH}_{2} \mathrm{OH}$ & B \\
\hline A & \\
\hline
\end{tabular}

Figure 5 Structure representing a triglyceride ester (a fat or oil) 
Table 1 Description of the levels of representation of matter in the chemical diagrams investigated in the study

\begin{tabular}{|c|c|c|c|c|c|}
\hline Diagrams & Description/ Purpose & Levels of Representation & Explanation & Mental model of chemistry & Assertion \\
\hline 1 Distillation & $\begin{array}{l}\text { Descriptive and illustrative } \\
\text {-The apparatus and their } \\
\text { function }\end{array}$ & Macroscopic & $\begin{array}{l}\text { Apparatus creates changes in } \\
\text { state from liquid-vapour-liquid }\end{array}$ & $\begin{array}{l}\text { Sub-microscopic of } \\
\text { liquid-vapour-liquid } \\
\text { states. }\end{array}$ & $1,2,3$ \\
\hline $\begin{array}{l}\text { Fractional } \\
\text { distillation }\end{array}$ & $\begin{array}{l}\text { Descriptive and } \\
\text { Explanatory and Illustrative }\end{array}$ & $\begin{array}{l}\text { Macroscopic and sub- } \\
\text { microscopic }\end{array}$ & $\begin{array}{l}\text { Apparatus creates changes in } \\
\text { state from liquid-vapour-liquid }\end{array}$ & $\begin{array}{l}\text { Sub-microscopic of } \\
\text { liquid-vapour-liquid } \\
\text { states. }\end{array}$ & $2,3,4$, \\
\hline $\begin{array}{l}\text { 2. Gravity and } \\
\text { vacuum distillation }\end{array}$ & $\begin{array}{l}\text { Filter paper in funnel, and } \\
\text { buchner funnel }\end{array}$ & Macroscopic & Separation of solid material & $\begin{array}{l}\text { Separating solid from liquid materials- } \\
\text { at a macroscopic level. }\end{array}$ & $1,2,3$ \\
\hline $\begin{array}{l}\text { 3. Colour } \\
\text { chromatography }\end{array}$ & $\begin{array}{l}\text { Parts of the apparatus and } \\
\text { their function }\end{array}$ & Macroscopic & $\begin{array}{l}\text { Variable rate depends on their } \\
\text { degree of solubility }\end{array}$ & $\begin{array}{l}\text { Molecular movement depends on its } \\
\text { solubility -links to sub-microscopic } \\
\text { level }\end{array}$ & $1,2,3$, \\
\hline 4. Equilibrium & Macroscopic observations & $\begin{array}{l}\text { Macroscopic plus } \\
\text { annotations at the sub- } \\
\text { microscopic level }\end{array}$ & $\begin{array}{l}\text { Identifying the reactions and } \\
\text { responses to change }\end{array}$ & Sub-microscopic movement & $1,2,3,4$ \\
\hline 5. States of matter & $\begin{array}{l}\text { Representation of three } \\
\text { states of matter using } \\
\text { spheres }\end{array}$ & $\begin{array}{l}\text { Symbolic representation } \\
\text { of the sub-microscopic } \\
\text { level }\end{array}$ & $\begin{array}{l}\text { Using the particulate nature of } \\
\text { matter to explain changes of state }\end{array}$ & $\begin{array}{l}\text { Linking the macroscopic level with the } \\
\text { sub-microscopic representation }\end{array}$ & 1,3 \\
\hline $\begin{array}{l}\text { 6. Reflux } \\
\text { equipment } \\
\text { (saponification) }\end{array}$ & $\begin{array}{l}\text { Boiling and reflux of a } \\
\text { liquid }\end{array}$ & Macroscopic & $\begin{array}{l}\text { Changing from liquid to gas and } \\
\text { back to liquid }\end{array}$ & $\begin{array}{l}\text { Refluxing process provides an } \\
\text { opportunity for the reaction to occur }\end{array}$ & $1,2,3,4$ \\
\hline $\begin{array}{l}\text { 7. Structural } \\
\text { formula }\end{array}$ & $\begin{array}{l}\text { Symbolic structural } \\
\text { representations }\end{array}$ & $\begin{array}{l}\text { Symbolic representation } \\
\text { of the sub-microscopic } \\
\text { level }\end{array}$ & $\begin{array}{l}\text { Limitations of the symbolic } \\
\text { representation of the sub- } \\
\text { microscopic level- }\end{array}$ & Picturing a double bond in a molecule & 2,3 \\
\hline 8. Titration curves & $\begin{array}{l}\text { Graph of the change in } \mathrm{pH} \\
\text { of a solution }\end{array}$ & Symbolic representation & $\begin{array}{l}\text { Connecting the changing } \mathrm{pH} \text { to } \\
\text { the changing chemical } \\
\text { composition }\end{array}$ & Reaction mechanism occurring & $2,3,4$ \\
\hline $\begin{array}{l}\text { 9. Indicators, salts } \\
\text { and buffers }\end{array}$ & $\begin{array}{l}\text { Picture of the colour of an } \\
\text { indicator in solutions of } \\
\text { varying } \mathrm{H}+\text { concentration }\end{array}$ & $\begin{array}{l}\text { Macroscopic } \\
\text { Symbolic level }\end{array}$ & $\begin{array}{l}\text { Identifying chemical change with } \\
\text { known indicators } \\
+\end{array}$ & $\begin{array}{l}\text { Chemical reaction of indicator to } \mathrm{H}+ \\
\text { concentration }\end{array}$ & $1,2,3,4$ \\
\hline $\begin{array}{l}\text { 10. Alcohols and } \\
\text { phenols }\end{array}$ & $\begin{array}{l}\text { Various symbolic } \\
\text { representations }\end{array}$ & $\begin{array}{l}\text { Symbolic representations } \\
\text { of the sub-microscopic }\end{array}$ & $\begin{array}{l}\text { Recognising chemical character } \\
\text { and linking to the physical }\end{array}$ & $\begin{array}{l}\text { Linking atomic structure with } \\
\text { chemical properties }\end{array}$ & $1,2,3$ \\
\hline
\end{tabular}




\begin{tabular}{|l|l|l|l|l|l|}
\hline & level & properties & \\
\hline $\begin{array}{l}\text { 11. Aldehydes and } \\
\text { ketones, carboxylic } \\
\text { acids }\end{array}$ & $\begin{array}{l}\text { Various symbolic } \\
\text { representations }\end{array}$ & $\begin{array}{l}\text { Symbolic representations } \\
\text { of the sub-microscopic } \\
\text { level }\end{array}$ & $\begin{array}{l}\text { Recognising chemical character } \\
\text { and linking to the physical } \\
\text { properties }\end{array}$ & $\begin{array}{l}\text { Linking atomic structure with } \\
\text { chemical properties }\end{array}$ & $1,2,3$ \\
\hline
\end{tabular}

